\title{
FORMULASI MASKER PEEL OFF ANTIOKSIDAN BERBAHAN AKTIF EKSTRAK DAUN SIRSAK (Annona muricata Linn.)
}

\author{
Deasy Novia Sari*, Nur Mita, Laode Rijai \\ Laboratorium Penelitian dan Pengembangan FARMAKA TROPIS \\ Fakultas Farmasi Universitas Mulawarman, Samarinda, Kalimantan Timur \\ *email: deasynovias@yahoo.com
}

\begin{abstract}
ABSTRAK
Masker peel-off merupakan sediaan gel yang dapat mengandung senyawa antioksidan dari bahan alam yang digunakan untuk perawatan kulit wajah. Daun sirsak (Annona muricata Linn.) tergolong antioksidan sangat kuat. Tujuan dari penelitian ini adalah untuk mengetahui aktivitas antioksidan ekstrak etanol daun sirsak dan stabilitas antioksidan masker peel-off ekstrak daun sirsak. Formula masker peel-off terdiri dari 0,5\% ekstrak etanol daun sirsak dengan kombinasi polivinil alkohol dan hidroksi propil metil selulosa sebagai gelling agent. Aktivitas antioksidan diuji menggunakan metode DPPH (1,1-Diphenyl-2-Picrylhidrazil). Hasil penelitian menunjukkan bahwa nilai $\mathrm{IC}_{50}$ dari ekstrak etanol daun sirsak dan masker peel-off ekstrak tersebut berturut-turut adalah 41,52 ppm dan 11,87 ppm. Dari penelitian ini dapat disimpulkan bahwa aktivitas antioksidan masker peel-off ekstrak daun sirsak empat kali lebih tinggi dibandingkan dengan aktivitas antioksidan ekstrak daun sirsak.
\end{abstract}

Kata kunci : Masker peel off, antioksidan, $\mathrm{IC}_{50}$

\begin{abstract}
ABTRACT
Peel-off mask is a gel formulation that contain antioxidant compounds from natural materials, that used for the treatment of facial skin. Leaves of the soursop (Annona muricata Linn.) classified as very powerful antioxidant. The purpose of this study are to determine the antioxidant activity of ethanol extract of soursop leaf antioxidants and stability of the peeloff mask soursop leaf extract. Formula peel-off mask comprised of 0,5\% ethanol extract of soursop leaves with a combination of polyvinyl alcohol and hydroxy propyl methyl cellulose as a gelling agent. The antioxidant activity was tested using DPPH (1,1-Diphenyl-2Picrylhidrazil). The results showed that the $I_{50}$ value of the ethanol extract of soursop leaves and peel-off mask the extract are respectively 41,52 ppm and 11,87 ppm. From this study it can be concluded that the antioxidant activity of peel-off mask soursop leaves extract is four times higher than the soursop leaves extract antioxidant activity.
\end{abstract}

Keywords: Peel-off mask, antioxidants, $I C_{50}$

\section{PENDAHULUAN}

Kulit merupakan organ yang pertama terkena dampak buruk polusi, paparan sinar ultraviolet yang dapat merusak kulit. Selain itu, aktivitas sehari-hari juga dapat menimbulkan masalah pada kulit terutama kulit wajah. Apabila kulit wajah tidak dibersihkan dan dirawat dengan teratur akan mengakibatkan sel kulit mati, menumpuk dan menghambat produksi kolagen, sehingga memicu terbentuknya garis-garis halus dan kerutan pada kulit. Perawatan 
kulit sangat diperlukan untuk memelihara agar kulit tetap sehat, indah dan terlihat bersih. Salah satu caranya dengan menggunakan masker wajah (Rahim, 2014).

Masker peel off dapat dibuat dari bahan alam yang mengandung senyawa antioksidan yang dapat membantu untuk merawat kulit wajah. Antioksidan merupakan suatu zat yang dapat menetralkan radikal bebas sehingga melindungi tubuh dari penyakit dengan cara mengikat radikal bebas dan molekul yang sangat reaktif yang dapat merusak sel (Budiarti, 2014). Radikal bebas (free radical) adalah suatu senyawa atau molekul yang mengandung satu atau lebih elektron tidak berpasangan pada orbital luarnya. Adanya orbital yang tidak berpasangan menyebabkan senyawa tersebut sangat reaktif mencari pasangan dengan cara menyerang dan mengikat elektron molekul yang berada disekitarnya.

Penggunaan antioksidan secara topikal dapat menurunkan radiasi sinar UV A yang dapat menyebabkan kulit menjadi gelap. Antioksidan topikal juga digunakan untuk mencegah penuaan dan radiasi sinar UV yang menyebabkan kerusakan kulit, perawatan untuk mencegah kulit mengkerut dan erythema yang disebabkan oleh inflamasi seperti sebuah lapisan yang melindungi kulit (Bauman, 2002).

Daun sirsak banyak digunakan sebagai obat herbal untuk mengobati berbagai penyakit. Kandungan senyawa dalam daun sirsak antara lain steroid atau terpenoid, flavonoid, kumarin, alkaloid dan tanin. Senyawa flavonoid pada daun sirsak berfungsi sebagai antioksidan (Adri, 2013).

\section{METODE PENELITIAN}

\section{Alat dan Bahan}

Alat-alat yang digunakan adalah toples kaca, corong Buchner, kertas saring, timbangan analitik, rotary evaporator, water bath, labu ukur, gelas kimia, batang pengaduk, pipet ukur, pipet tetes, corong kaca, sentrifuge, mortir, stemper, spektrofotometer, sendok tanduk, termometer, spatel logam dan cawan porselen. Bahan yang digunakan sebagai zat aktif adalah daun sirsak (Annona muricata) yang diambil di daerah kota Samarinda, Kalimantan Timur. Sedangkan bahan tambahan yang digunakan yaitu polivinil alkohol, HPMC, propilenglikol, metilparaben, propilparaben, SLS, dan aquadest serta DPPH dan metanol untuk pengujian antioksidan.

\section{Preparasi Bahan Aktif}

Daun sirsak (Annona muricata) dikumpulkan lalu disortasi, dipilih daun yang masih baik dilihat dari tampilan fisiknya. Daun sirsak kemudian dicuci dan dirajang kemudian dikeringkan di tempat yang tidak terkena cahaya atau sinar matahari secara langsung. Kering atau tidaknya sampel dilihat melalui tampilan fisik sampel yaitu dari warna daun yang awalnya hijau berubah menjadi warna coklat, pada penelitian ini tidak dilakukan pengukuran kadar air dari bahan. Ditimbang dan diperoleh berat serbuk simplisia daun sirsak yang siap diekstraksi.

\section{Ekstraksi Bahan Aktif}

Sampel kering yang telah diketahui beratnya dilakukan pengekstraksian sampel dengan cara maserasi didalam wadah kaca menggunakan pelarut etanol 96\% selama 3 hari. 
Kemudian dilakukan pengadukan setiap 24 jam, begitu seterusnya hingga didapat pelarut berwarna bening. Maserat yang diperoleh dipekatkan dengan menggunakan rotary evaporator pada suhu $40^{\circ} \mathrm{C}$ sampai pelarut habis menguap. Hasil ekstrak yang telah dipekatkan lalu diangin-anginkan hingga diperoleh ekstrak kental. Ekstrak yang diperoleh kemudian ditimbang beratnya.

\section{Pengujian Antioksidan Ekstrak Daun Sirsak}

Diambil 2 mL larutan ekstrak kemudian ditambahkan $2 \mathrm{~mL}$ larutan DPPH 40 ppm ke dalam tabung reaksi dan divortex. Dibiarkanditempat gelap pada suhu kamar selama 30 menit. Sebagai kontrol negatif digunakan $2 \mathrm{~mL}$ pelarut, ditambah $2 \mathrm{~mL}$ larutan DPPH 40 ppm. Kemudian diukur absorbansinya dengan menggunakan spektrofotometer Uv-Vis.

\section{Pembuatan Masker Peel Off}

Pembuatan basis masker peel off dimulai dengan menimbang semua bahan yaitu polivinil alkohol, propilenglikol, HPMC, propil paraben, metil paraben, SLS dan air suling. Dibuat gelling agent dengan cara mengembangkan HPMC dalam air suling dingin hingga mengembang dan PVA dalam air suling panas hingga mengembang sempurna selama satu hari, kemudian diaduk menggunakan magnetic bar. Kedua massa tersebut kemudian dicampurkan hingga homogen. Dilarutkan metil paraben dan propil paraben dalam propilenglikol hingga terlarut. Kemudian ditambahkan SLS dan diaduk hingga larut. Dicampurkan semua bahan yang terlarut dan membentuk massa yang homogen dengan propilenglikol kedalam gelling agent yang telah terbentuk lalu diaduk sampai terbentuk massa yang homogen. Ditambahkan dengan ekstrak daun sirsak dengan basis dan digerus perlahan sampai homogen. Ditambahkan air suling yang masih tersisa kedalam massa yang telah tercampur kemudian diaduk hingga homogen.

Tabel 1. Formulasi Masker Peel-off

\begin{tabular}{lc}
\hline \multicolumn{1}{c}{ Bahan } & Konsentrasi (\%) \\
\hline Ekstrak daun sirsak & 0,5 \\
Polivinil alkohol & 15 \\
HMPC & 1 \\
Propilenglikol & 12 \\
Propil paraben & 0,02 \\
Metil paraben & 0,5 \\
SLS & 0,1 \\
Air suling ad & $5 \mathrm{Ml}$ \\
\hline
\end{tabular}

\section{Pengujian Antioksidan Masker Peel Off Ekstrak daun Sirsak}

Diambil 5 gram sediaan masker peel off dilarutkan dengan $100 \mathrm{~mL}$ larutan metanol. Setelah homogen diambil $2 \mathrm{~mL}$ kemudian ditambahkan $2 \mathrm{~mL}$ larutan DPPH 40 ppm ke dalam tabung 
reaksi dan divortex. Selanjutnya dibiarkan ditempat gelap pada suhu kamar selama 30 menit. Kemudian diukur absorbansinya menggunakan spektrofotometer Uv-Vis.

\section{HASIL DAN PEMBAHASAN}

\section{Pengujian Antioksidan Ekstrak Daun Sirsak (Annona muricata)}

Pengujian aktivitas antioksidan ekstrak daun sirsak dilakukan dengan menggunakan metode DPPH (1,1-difenil-2-pikrilhidrzail). DPPH merupakan radikal bebas yang stabil dan tidak membentuk dimer akibat delokalisasi dari elektron bebas pada seluruh molekul. Delokalisasi elektron bebas ini juga mengakibatkan terbentuknya warna ungu pada larutan DPPH, sehingga bisa diukur absorbansinya pada panjang gelombang sekitar $520 \mathrm{~nm}$. Ketika larutan DPPH dicampur dengan senyawa yang dapat mendonorkan atom hidrogen, maka warna ungu dari larutan akan hilang seiring dengan tereduksinya DPPH.

Pengujian aktivitas antioksidan ektrak daun sirsak dimulai dengan membuat seri konsentrasi larutan ekstrak daun sirsak kemudian diambil $2 \mathrm{~mL}$ dari masing-masing dari seri konsentrasi dan ditambahkan $2 \mathrm{~mL}$ DPPH 40 ppm. Kemudian larutan ekstrak dan DDPH yang telah tercampur dihomogenkan menggunakan vortex. Setelah itu sampel diinkubasi selama 30 menit agar DPPH dapat bereaksi optimal dengan antioksidan yang terdapat pada ekstrak daun sirsak. Setelah diinkubasi, dilakukan pengukuran absorbansi dari DPPH menggunakan spektrofotometer Uv-Vis. Peredaman antioksidan terhadap radikal bebas ditandai dengan perubahan warna DPPH dari ungu menjadi kuning. Uji aktivitas antioksidan dengan menggunakan metode ini dapat diamati berdasarkan dari hilangnya warna ungu akibat tereduksinya DPPH oleh antioksidan. Intensitas warna dari larutan uji diukur melalui spektrofotometri UV-Vis pada panjang gelombang sekitar $520 \mathrm{~nm}$. Hasil persen inhibisi tersebut disubstitusikan dalam persamaan linear. Hasil dari substitusi persen inhibisi tersebut kemudian diinterpretasikan sebagai IC $_{50}$. Persen inhibisi adalah perbandingan antara selisih dari absorbansi blanko dan absorbansi sampel dengan absorbansi blanko. Persen inhibisi digunakan untuk menentukan persentase hambatan dari suatu bahan yang dilakukan terhadap senyawa radikal bebas. IC $\mathrm{IC}_{50}$ didefinisikan sebagai jumlah antioksidan yang diperlukan untuk menurunkan konsentrasi awal DPPH sebesar 50\%. Metode ini memiliki keuntungan yaitu lebih sederhana dan waktu analisis lebih cepat. Berdasarkan penelitian yang dilakukan menunjukkan adanya aktivitas antioksidan pada ekstrak daun sirsak. Pada konsentrasi ekstrak 20 ppm, 30 ppm, 40 ppm, 50 ppm dan 60 ppm masing-masing mampu menghambat $25,58 \%, 35,82 \%, 48,14 \%, 62,82 \%$, dan $68,95 \%$ radikal bebas. Nilai $\mathrm{IC}_{50}$ dari 
ekstrak daun sirsak tersebut adalah 41,52 ppm. Dari data tersebut dapat disimpulkan bahwa antioksidan ekstrak daun sirsak berada dalam range antioksidan kuat, hal tersebut dapat dilihat dalam tabel 2. Penurunan nilai absorbansi DPPH mempunyai arti bahwa telah terjadinya penangkapan radikal DPPH oleh sampel. Dengan penangkapan radikal tersebut mengakibatkan ikatan rangkap diazo pada DPPH berkurang sehingga terjadinya penurunan absorbansi.

Tabel 2. Pengujian Antioksidan Ektrak Daun Sirsak

\begin{tabular}{|c|c|c|c|c|c|c|c|}
\hline \multirow{2}{*}{$\begin{array}{c}\text { Konsentrasi } \\
\text { Sampel } \\
\text { (ppm) }\end{array}$} & \multicolumn{3}{|c|}{ Absorbansi Sampel } & \multirow[b]{2}{*}{$\begin{array}{l}\text { Rata- } \\
\text { rata }\end{array}$} & \multirow[b]{2}{*}{$\begin{array}{l}\text { \% Aktivitas } \\
\text { Antioksidan }\end{array}$} & \multirow[b]{2}{*}{$\begin{array}{l}\text { Nilai } \\
\text { IC }_{50}\end{array}$} & \multirow[b]{2}{*}{ Keterangan } \\
\hline & I & II & III & & & & \\
\hline 20 & 0,385 & 0,374 & 0,373 & 0,386 & 25,589 & & \\
\hline 30 & 0,32 & 0,310 & 0,316 & 0,318 & 35,825 & & \\
\hline 40 & 0,258 & 0,255 & 0,257 & 0,257 & 48,148 & 41,521 & Kuat \\
\hline 50 & 0,179 & 0,182 & 0,191 & 0,184 & 62,828 & & \\
\hline 60 & 0,153 & 0,15 & 0,158 & 0,154 & 68,956 & & \\
\hline
\end{tabular}

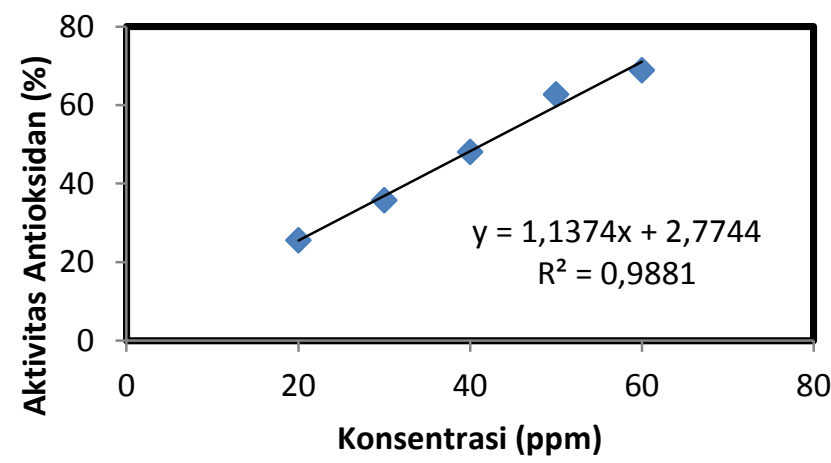

Gambar 1. Grafik Pengujian Antioksidan Ekstrak Daun Sirsak

Ditentukan persamaan regresi dan untuk selanjutnya dari persamaan diplotkan aktivitas $50 \%$ sehingga diperoleh harga konsentrasi efektif $\left(\mathrm{IC}_{50}\right)$. Semakin kecil nilai $\mathrm{IC}_{50}$ berarti semakin tinggi aktvitas antioksidan.

\section{Pembuatan Masker Peel Off}

Basis masker peel off dibuat dengan menggunakan HMPC sebagai gelling agent dan berfungsi sebagai peningkat viskositas dari basis masker peel off. Polivinil alkohol digunakan sebagai filming agent yang dapat membentuk lapisan film yang elastis sehingga 
formula masker peel off dapat dikelupas. Pada basis juga ditambahkan propilenglikol, digunakan sebagai humektan yang dapat mencegah kehilangan zat pembawa dari sediaan sehingga proses sineresis dapat dicegah, selain itu propilenglikol juga dapat meningkatkan viskositas dari sediaan, dimana sediaan diharapkan cukup kental sehingga mudah dioleskan pada kulit wajah tetapi masih dapat mengalir. Untuk mencegah timbulnya bakteri dan jamur pada sediaan dalam basis juga ditambahkan pengawet, yaitu metilparaben dan propilparaben. Digunakan dalam bentuk kombinasi karena dapat meningkatkan efeknya terhadap bakteri dan jamur tersebut. Sebagai pelarut digunakan aquadest.

\section{Pengujian Aktivitas Antioksidan Masker Peel Off}

Pengujian aktivitas antioksidan masker peel off juga dilakukan dengan menggunakan metode DPPH. Sebanyak 5 gram formula masker peel off dilarutkan dengan $100 \mathrm{~mL}$ larutan metanol, dilakukan penyaringan dan sentrifuge. Tujuan dilakukan dari penyaringan dan sentrigue adalah agar didapatkan larutan yang bening sehingga tidak mengganggu absorbansi saat diukur menggunakan spektrofotometer. Setelah homogen diambil 2 mL kemudian ditambahkan 2 mL larutan DPPH 40 ppm ke dalam tabung reaksi dan divortex. Selanjutnya dibiarkan ditempat gelap pada suhu kamar selama 30 menit. Kemudian diukur absorbansinya menggunakan spektrofotometer Uv-Vis.

Berdasarkan penelitian yang dilakukan menunjukkan adanya aktivitas antioksidan pada masker peel off. Pada formula masker peel off dengan konsentrasi ekstrak daun sirsak 5 ppm, 10 ppm, 15 ppm, 20 ppm, dan 25 ppm masing-masing mampu menghambat 29,83\%, $47,66 \%, 62,83 \%, 69,59 \%$ dan $75,22 \%$ radikal bebas. Nilai IC 50 dari formula masker peel off ekstrak daun sirsak adalah 11,87 ppm.

Tabel 3. Pengujian Antioksidan Masker Peel Off

\begin{tabular}{ccccc}
\hline $\begin{array}{c}\text { Konsentrasi } \\
\text { Sampel }(\mathrm{ppm})\end{array}$ & $\begin{array}{c}\text { Absorbansi } \\
\text { Sampel }\end{array}$ & $\begin{array}{c}\text { \% Aktivitas } \\
\text { Antioksidan }\end{array}$ & Nilai IC 50 & \multirow{2}{*}{ Keterangan } \\
\hline 5 & 0,555 & 29,83 & & \\
10 & 0,414 & 47,66 & & \\
15 & 0,294 & 62,83 & 11,87 & Sangat Kuat \\
20 & 0,240 & 69,65 & & \\
25 & 0,196 & 75,22 & & \\
\hline
\end{tabular}

Dari hasil tersebut diketahui aktivitas antioksidan masker peel off ekstrak daun sirsak empat kali lebih tinggi dibandingkan dengan aktivitas antioksidan ekstrak daun sirsak. Hal 
tersebut dapat dikarenakan adanya zat tambahan seperti pengawet yang dapat mencegah terjadinya reaksi oksidasi sehingga meningkatkan aktivitas antioksidan dari sediaan.

Semakin tinggi konsentrasi sampel maka semakil kecil absorbansi DPPH karena terjadinya penangkapan radikal DPPH oleh sampel yang mengakibatkan ikatan rangkap diazo pada DPPH berkurang sehingga terjadi penurunan absorbansi. Semakin tinggi konsentrasi sampel maka semakin tinggi pula persen aktivitas antioksidan (gambar 2).

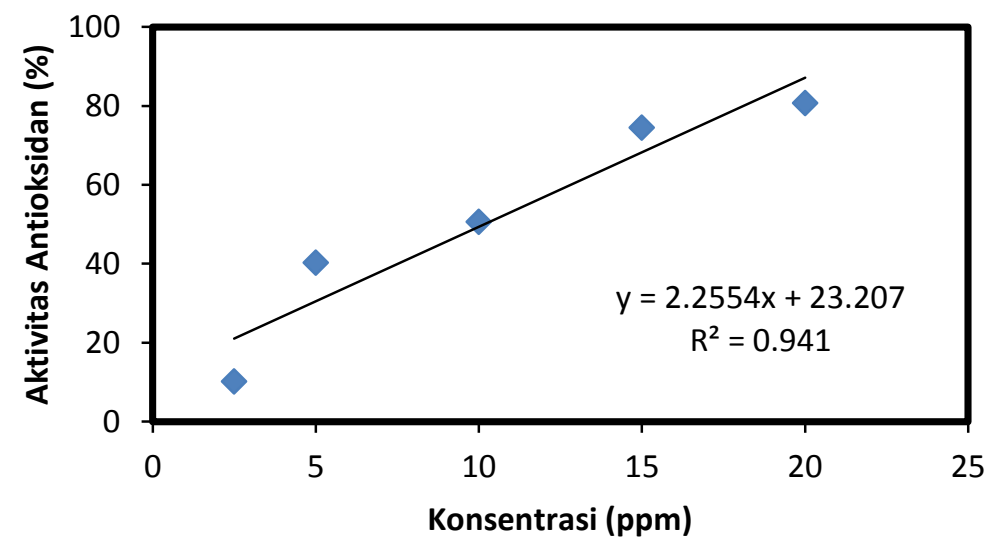

Gambar 2. Grafik Pengujian Antioksidan Masker Peel Off

\section{KESIMPULAN}

Dari penelitian ini dapat disimpulkan bahwa aktivitas antioksidan masker peel off ekstrak daun sirsak empat kali lebih tinggi dibandingkan dengan aktivitas antioksidan ekstrak daun sirsak.

\section{DAFTAR PUSTAKA}

Adri, D, dkk. 2013. Aktivitas Antioksidan dan Sifat Organoleptik Teh Daun Sirsak (Annona muricata Linn.) Berdasarkan Variasi Lama Pengeringan. Jurnal Pangan dan Gizi Vol. 04 No. 07 Tahun 2013.

Baumann, L. 2002. Cosmetic Dermatology : Principles and Practice. The McGraw-Hill Companies : New York.

Budiarti, A, dkk. 2014. Aktivitas Antioksidan Fraksi Kloroform Ekstrak Etanol Daun Sirsak (Annona muricata L.) dan Identifikasi Kandungan Senyawa Kimianya. Prosiding SNST ke-5 Tahun 2014 Fakultas Teknik Universitas Wahid Hasyim Semarang.

Molyneux, P. 2004. The Use of Stable Free Radical Diphenylpicryhydrazil (DPPH) for Estimating Antioxidant Activity. Songklanakarin J. Sci. Technol. Volume 6 No.2 Tahun 2004.

Rahim, F, dkk. 2014. Formulasi Masker Peel Off Ekstrak Rimpang Rumput Teki (Cyperus rotundus L.) sebagai Anti Jerawat. Prosiding Seminar Nasional dan Workshop "Perkembangan Terkini Sains Farmasi dan Klinik IV" tahun 2014. 